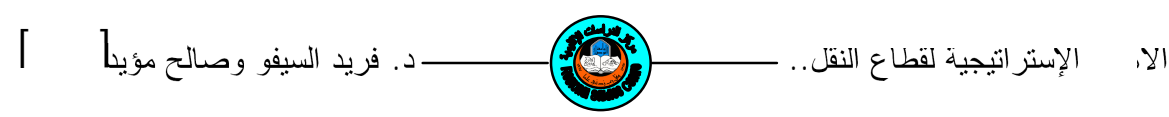

الاهميه الإستر اتيجيه لقطاع النقل واتاره وي رهع وتطوير مناطق الجلب السياحي في سوريا: در اسه اهتصاديه إحصائيه

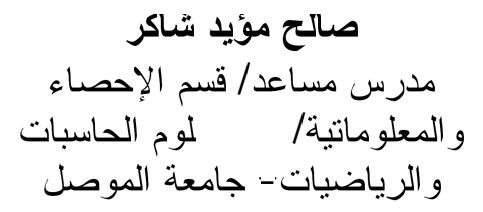

صاكح مؤيل شاكر

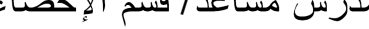

و الرياضيات - جامعة المولية علوم الموصلت

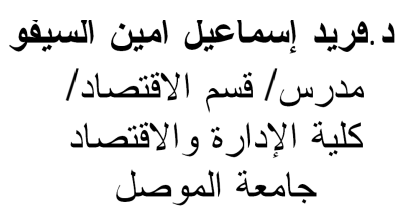

الفكرة الأساسية لهذه الاراسة تأخذ بنظر الاعتبار وجود علاقة قوية بين

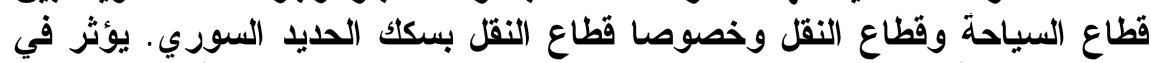

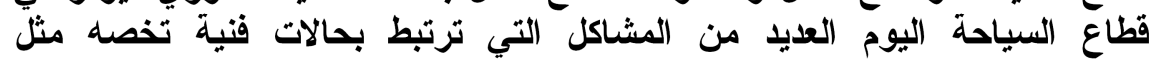

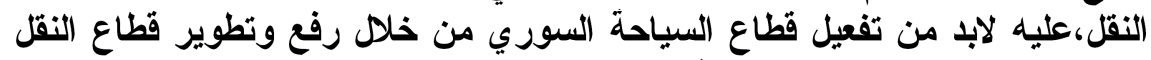

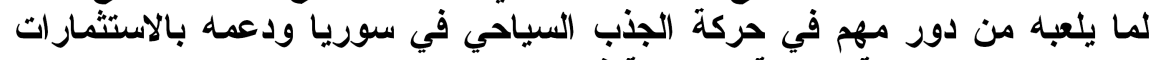
لتقديم الحلول الناجحة للحركة السياحية فيها.

مقدمه

اضحت السياحة احد معايير ودعائم الحاضرة والاقتصساد وضرورة ملحة

للإنسانية لما لها من سمات ايجابية لمنفعة الإنسان سيما وان مشكلة تلوث الاوساط الاربعة (التربة و الماء و الهو اء و المجال السمعي) وكذلك الإرهاق العضلي والنفسي و الذهني لدى الإنسان في كتير من دول العالم دفع ذلك ولك

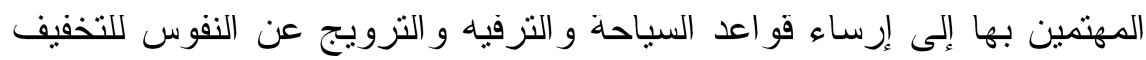
من وطاة هذه الظواهر لما لها من ناتير على حياة الفرد فاعدت الكثير من الدراسات و البحوث و النشرات في مجالات هذا القطاع.إن توفير قطاع نقل هره 
متكامل يشمل جميع الانماط مع التزكيز على قطاع النقل بسكك الحديد في

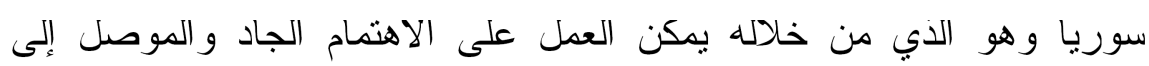
مستوى في الاستثمار في قطاع السياحة.

إن قطاع السياحة يحتاج إلى عدة مجالات يمكن من خلالكها رفع مستوى هذا القطاع.إن الكتير من الدول تتبع تخطيط معين وضمن اولويات منتابعة في ترتيب هذه المجالات من اجل الحيلولة للوصول إلى مستوى من الاستتمار لقطاع السياحة. يو اجه قطاع السياحة مشاكل عديدة ومختلفة تتعلق بمجالات فنية تخص قطاع السياحة ومنها قطاع النقل لذلك لابد من إجر اء در اسة على قطاع السياحة في سوريا من اجل الوقوف على ما يعانيه من تلك المشاكل لإيجاد الحلول الناجحة لها.

ان الهدف من الدراسة هو تفعيل السياحة السوريا من خلال رفع وتطوير قطاع النقل لما له دور مهم في هذا المجال، حيث بمكن صباغة فرضية البحث إن لوسائل النقل دور في قطاع السياحة في سوريا.استخدم الباحث اسلوب المنهج التحليلي و الوصفي في در اسة و اقع الخدمات في سوريا و افاق نطور ها من خلال عدة متغير ات مستعينا ببعض البيانات المنوفرة من مصادر ها الرسمبة وشبه الرسمبة و على هذا الاساس ستتضمن الدر اسة قسمين:

\section{I ـ مفهوم وتعريف السياحه}

بدات السياحة تلفت انتباه المسؤؤلين،وتستدعي اهنمام ونظر الباحتين،نظر ا لاتار ها الاقتصادية الهامةهولما نوفره في زيادة في الدخل القومي لما بسهم في التتمية الاجتماعية و الاقتصادية. فلانفاق الذي يكون عادنا لقاء خدمات يحصل عليها السائح مقابل سلع يشتريها،يشكل موردا اقتصاديا للمنطقة الني تستقطب لإبه 
السياح ومجال لنتغيل الايدي العاملة ولذلك برز المفهوم الاقتصادي للسياحة وما بمكن ان تلعبه السياحة من دور في النطور الاقتصادي للبلدان. ان اصل كلمة السباحة هو (Tourism) من (Tour): رحلة و اطلقت على دورئه طلاب العلم الانكليزي في اوربا (Tourist)في القرن التامن عشر و انتشرت هذه الكلمة إلى اللغات الاخرى واستعملت للسائح و السباحة ابي التحرك في رحلة لغرض المتعة و النزفيه او الصحة وليس لاكتساب المال او لإقامة الدائمة

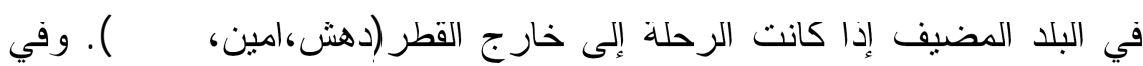
عام ץسوا ارتات لجنة الخبراء السياحيين في عصبة الامم تعريفا حددت

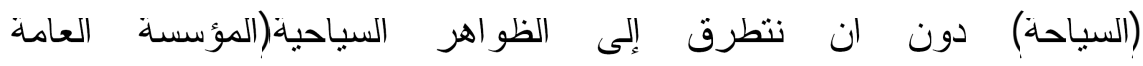

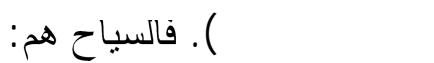
1 -الاشخاص الذين يقومون برحلة عائلية او للمتعة او لاسباب صحية. r -الاشخاص الذين يحضرون اجتماعات علمية،إدارية،سياسية،دينية او رياضية. ب - الذين بسافرون لانجاز الاعمال. ع -المشاركون في الرحلات البحرية على السفن ولو قلت زيارة السفن على ربع ساعة.

\section{الاهميه الاقتصاديه للسياحه}

السباحة صناعة مربحة متتامية سريعة المردود وهي فوق ذلك تختلف عن

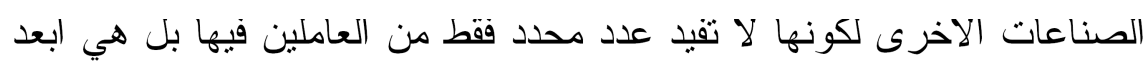
هدفا واوسع غاية وينتقع من مردودها اكبر عدد من المواطنين فضالا ان لها

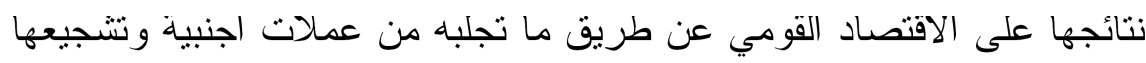
لسلسلة كبيرة من الخدمات السياحية ونقديم مجالات اخرى من العمل لاناس كتيرين من الإداريين و الفنيين والعمال المهرة ومجالات اخرى مشجعة عن 
طريق التخطيط و الاستتمار في الفنادق و الخدمات السياحية العامة والتزويج و التسويق وذلك عن طريق الاثر المضاعف الذي بيين مقدار الزيادة في الدخول الناجحة عن كل زيادة في الاستثمار فهو في السياحة اعلى هنه في اي صناعة بل هو مضاعف في الدول النامية (r -ع)وفي الدول الصناعية من (V- V- (V) فالسياحة ظاهرة اقتصادية و اجتماعية وقطاع إنتاجي هام تتافس القطاعات الإنتاجية الاخرى في الدول النامية ونشاط تتعاون عدة قطاعات على توفير مستلزماته مما يؤدي تاثير مباشر في التنمية الاقتصادية وتتشيط دورتها. اهم الاسس لفيام حركه السياحه.

نتيجة لتزايد الاهتمام بالسياحة،ققط ظهرت الحاجة لدراسة الموارد السياحية المتوفرة ليتسنى تحديد اهمبة المواقع السباحية. وبما ان صناعة لهابة السياحة صناعة مركبة فهي لا تخنلف عن غيرها في الصناعات الاخرى الني لها اسسها التي تقوم عليها وهي: (العقبلي، (199): الموارد الاولية وتثمنل بالموقع الجغر افي و الطقس و المواقع السياحية-التاريخية و الدينية و الطبيعية؛ وسائل الإنتاج وهي البد العاملة و المر افق العامة و القو انين و النسهيلات ومكاتب السفر؛ اسو اق التصدير وتتمنل بالترويج وطرق التسويق.

\section{الاستتمار السياحي وسبل تنشيطه وعلاقته بالتتميه الاقتصاديه}

إن للاستثمار السياحي اهمية يتحدد مداها في إن الاستثمار السياحي لا لا

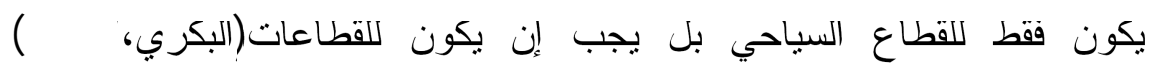
الاخرى نم الدعوة إلى إقامة استتمارات اقتصادية مخططة ومنو ازنة لكافة القطاعات الاقتصادية بما فيها القطاع السياحي وهذا بعني بان اتار السياحة 


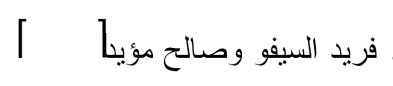
الاهمية الإسنر اتيجية لقطاع النقل..

سنطرق ابو اب معظم المشاريع و القطاعات الاقتصادية للاقتصاد القومي وعلى

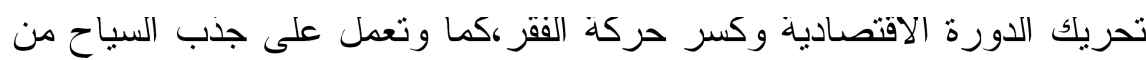

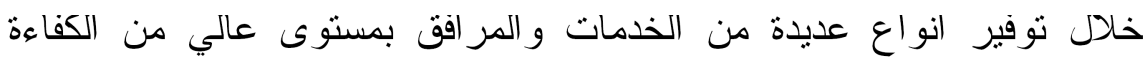

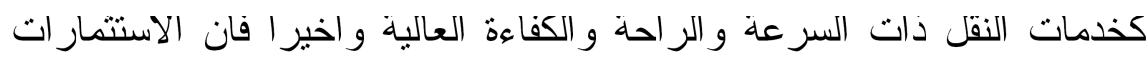
السباحبة تعتبر مسالة هامة تقود إلى اثارها الايجابية على مسالتين النطور

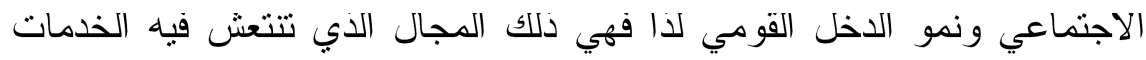
العامة وتتهيا من خلاله مرافق عصرية للراحة والنسلية لعموم المواطنين إضافة إلى انها وسيلة فعالة للترفيه بتراث وحضارة القطر وجذب السياح من

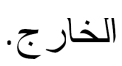
ونظر ا للاهمية الاقتصادية للسياحة فقد نطورت الحركة السياحية في العالم

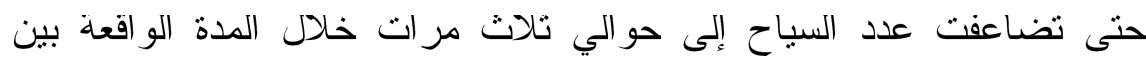

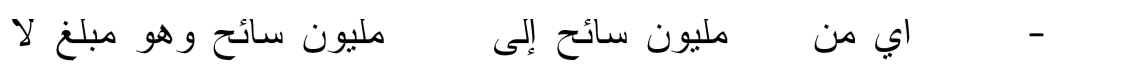

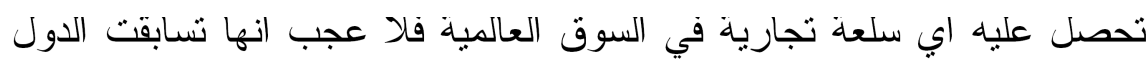

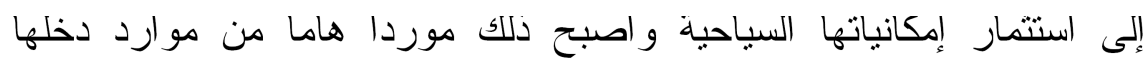

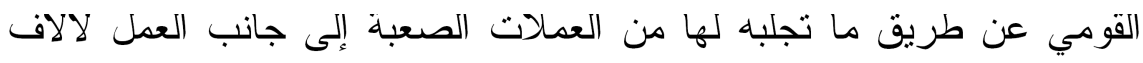
من ابنائها.

\section{مفومات السياحه في سوريا}

احدتت وزارة السياحة في سوريا بموجب المرسوم رقم اع لعام $19 V T$

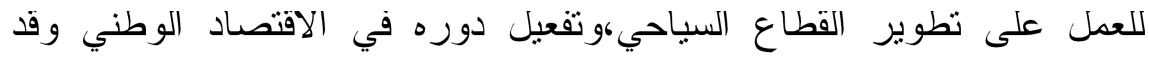

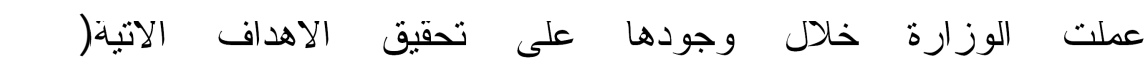

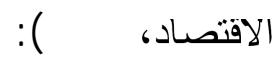


1 -تفعيل العلاقات مع الاسواق المصدرة للسياح باتجاه سوريا وبشكل

خاص السوق العربية و الإسلامية، وتامين خصوصية مستلزماتها. r - استعادة حركة القدوم الاوربية و الامريكية وتطوير احتباجاتها. ب -اتخاذ الإجراءات العملية اللازمة لفتح اسواق جديدة و استقدام السياح العرب من بلاد الاغتر اب و السوريين منهم بشكل خاص،وفتح قنو ات الاتصال معهم. و إذا بحتنا في مقومات السياحة في سورية فإننا بمكن ان نذكر ما يلي:

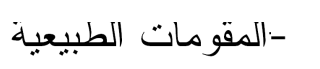

تمنلك سوريا الثشاطئ البحري الجمبل وكذلك الغابات و الجبل و الطبيعة الخلابة و المباه و المناخ المعتدل و لا يخفى ايضا الموقع الجغر افي المتميز ،مما جعلها تلبي الرغبات المختلفة للسياح باختلاف اصنافهر. ويمكن ان نصنف ولف لهن

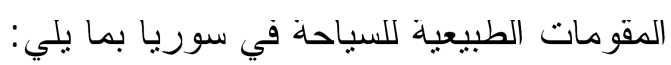
المصايف: وهي الاماكن الني تؤدي غرض الاستجمام في الصبف، و المصايف تلعب دورا اساسيا في جذب السياح على اعنبار انها ثكون مقصدا لجزء كبير من سكان العالم الذين ليس لديهم تغيرات مناخية حادة جدا وهذا ما

$$
\text { ينطبق على معظم سكان اوربا. }
$$

إن سورية تمنلك مناطق اصطياف كتيرة جدا يتركز معظمها في محافظة دمثق نذكر منها في الجدول التالي وكما يلي(سلسلة العلوم الاقتصادية، 0 . ب): الجدول -1: مناطق الاصطياف في سوريا

\begin{tabular}{|c|c|}
\hline عدد المصايف & المحافظة \\
\hline$r$. & دمثق \\
\hline$\mu$ & | درعا \\
\hline 0 & حصلجحماه \\
\hline 7 & اللاذقبة+طرطوس \\
\hline$\varepsilon$ & حلب+|ادلب \\
\hline 1 & الحسكة \\
\hline
\end{tabular}




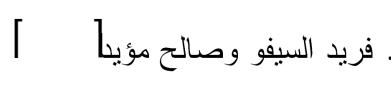
الاهمية الإستر اتيجية لقطاع النقل.

اماكن السباحة العلاجية: ويقصد بها ينابيع المباه المعدنية الحارة التي

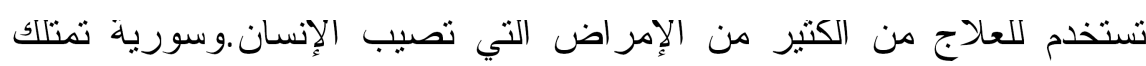
العديد من هذه المراكز العلاجية الني تصلح ان تكون مر اكز جذب سياحي لإني

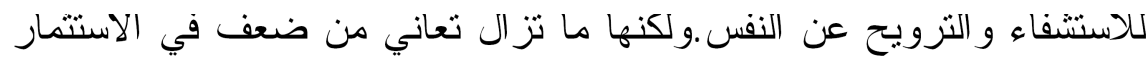

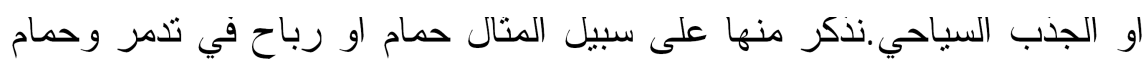
الشيخ عيسى في ادلب. ج- الثُو اطئ:إن اول ما بخطر ببال الإنسان عند الحديث عن السياحة هو

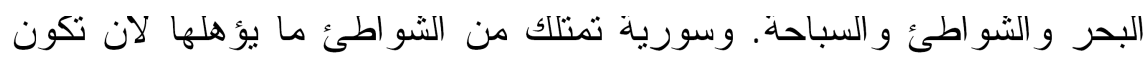

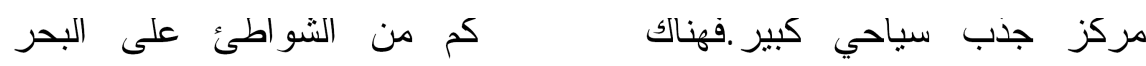
المتوسط،وتتميز هذه الثُواطئ بتتوعها بين الرملي و الصخري من جهنه،

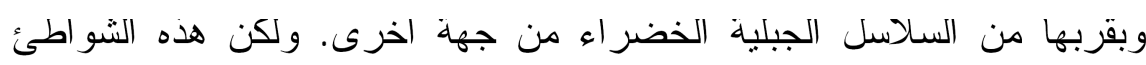
غير مستثمرة بالثكل الذي يجعل منها مصدر دخل سباحي لسورية. المو اقع الاترية و المتاحف:

لقد كانت سوريا منذ القدم مهذا للحضار ات عديدة،ومن الحضارات الني

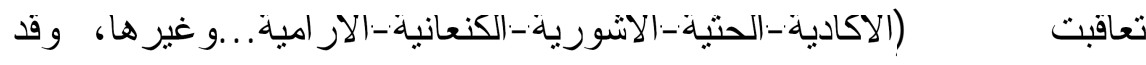

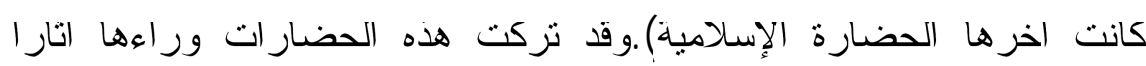
عظيمة تشكل حاليا ذخيرة تمنح سوريا عو امل جذب سياحية هامة.

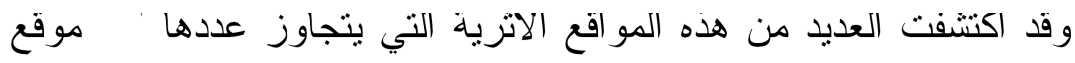

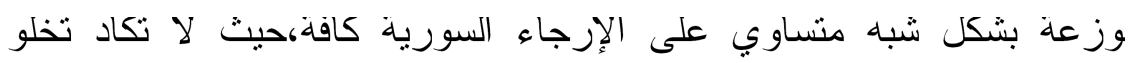

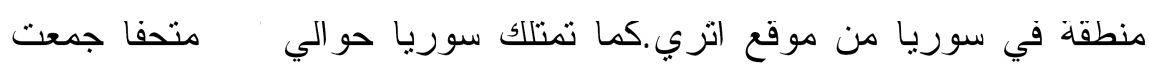

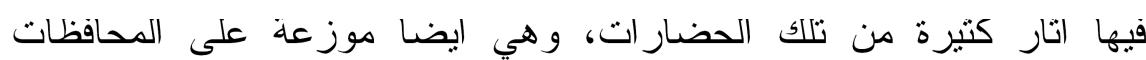

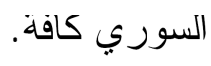


و هناك مقومات اخرى للسباحة في سوربا نذكر منها المعارض كمعرض دمثق الدولي ومعرض الزهور و المعارض الاقتصادية الاخرى المتخصصة. وكذلك نذكر المهرجانات كمهرجان المحبة ومهرجان البادية وغيرها.و لا ننسى الاماكن المقدة الني تجنذب سباحا كتيرين.

\section{r. مفهوم وتعريف النفل}

يعد النقل من الخدمات التي يجب نوفرها كاحد مجالات السياحة و النئي تلعب دور مهم في ذلك.ويقصد بالنقل هو الوسيلة الني بمكن استخدامها للوصول إلى مكان محدد ضمن كلفة محددة.و النقل انواع فهناك النقل البري و الذي يُنتمل على كافة انو اع العربات ومنها السيار ات و السكك الحديدية.و النوع التاني هو النقل البحري و الذي يشمل كافة انواع البواخر ووسائل النقل النهزي.والنوع الثالث هو النقل الجوي والذي بشمل كافة انواع الطائرات و المطار ات.

\section{الاهميه الاقتصاديه للنقل}

نظر ا للاهمية الكبيرة لهذا النوع من الخدمات السياحية نجد ان التخطيط لمنل هذا النوع من الخدمات يسهل مهمة وصول السائح إلى الموقع السياحي بكل تقة وارنباح،دلك لان السائح بنفق خارج بلده اكتر او اقل من نصف امو اله على النقل والنصف الاخر ينققه على الخدمات المكملة كخدات الإيواء السياحي و الخدمات العامة الاخرى حيث ينفق بحدود سع\% من مجموع إنفاقه على جميع وسائل النقل. 


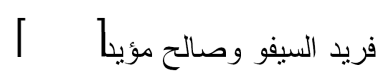
الاهمية الإسنر اتيجية لقطاع النقل..

ويجب علينا ملاحظة ان هنالك من العوامل ما يؤنز في النقل السياحي

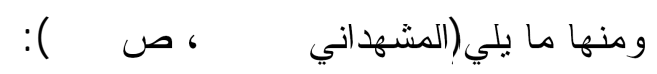

ا - نوع وسيلة النقل: وتشمل كافة وسائل البرية و البحرية و الجوية و اكتر

المواقع السياحية تتاثر بالطرق البريذ وخاصة طرق السيارات وسكك الحديد

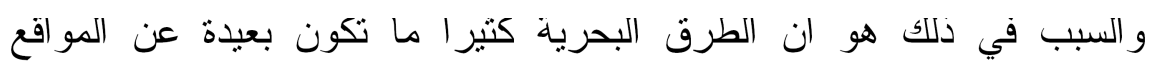

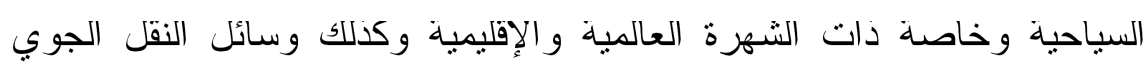
كثير ا ما نكون متوسطة او قريبة من مر اكز العو اصم او المحافظات تخدم قليلا حركة ور غبة السائح في التمتع في المشاهدة.

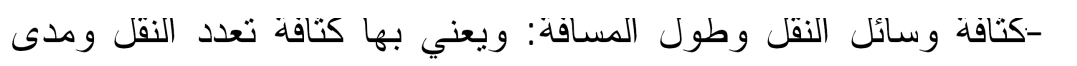
كفايتها او مدى مرونتها حيث انه زادت كتافة وسائل النقل كلما كان هناك مجال كالكال للاختبار والمفاضلة.وطرق النقل الاكثر كتافة تسمح للمسافرين بالاختبار كما

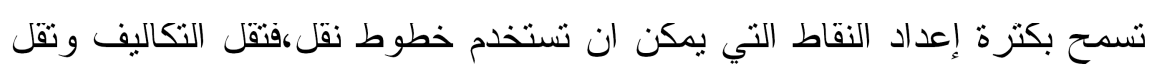
الاجور وتعتمد خطوط النقل الكتيفة على حجم المرور و على طبيعة المؤسسات

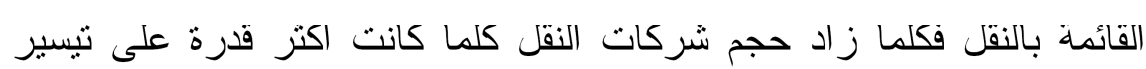
خطوط النقل اكتر كفاءة و اكتر قدرة على تخفيض اجور ها. ب - خطوط النقل: لخطوط النقل و اتجاهاتها اهمبذ كبيرة في النقل السياحي

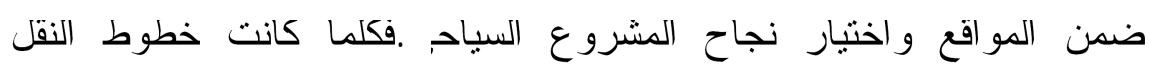

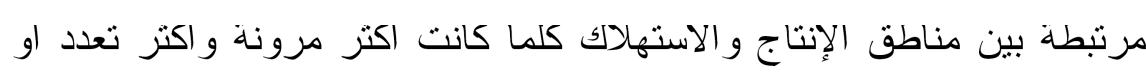

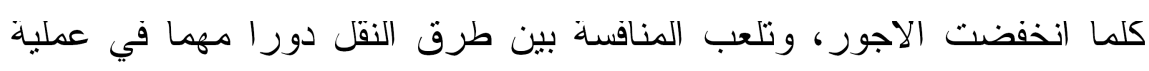
النقل وفي اجور كلفة النقل ففي حالة وجود طريقين متتاسبين بين نقطتين او اولئ

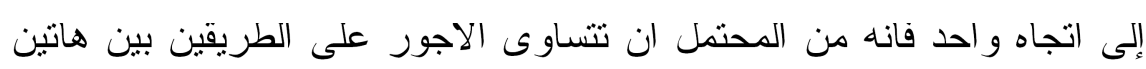
النقطنين بالرغم من ان الطريقين لا بنساويان في الطول. 
ع - الوقت وعلاقته بالمسافة ونوع الوسيلة: بوجه عام كلما طالت المسافة

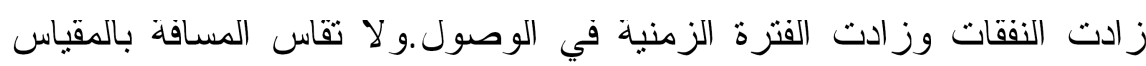
وبالخط المستقيم لان معظم المشاريع و المو اقع السياحية تقع في مناطق بعيدة او قريبة من الطرق وباختلاف انو اعها و إنما تقاس بالطول الطبيعي.

\section{وسائل النفل في سوريا}

تعد وسائل النقل من العناصر الاساسية والمهمة في مجال السياحة حيث المناطق السياحية المختلفة كلاتار و الثواطئ و المنتجعات و الاسواق التجارية و غبرها.إن تعدد وسائل النقل في سوريا انعش قطاع السياحة في سوريا وخاصة في مجال السكك الحديدية حيث هناك عدة خطوط حديدية بين المناطق و المحافظات السورية وسكك حديدية بين حلب و عدة مناطق منها (دير الزور و الرقة وحماه وحمص ودمشق و اللادقبة)، كذلك بين اللادقبة وعدة مناطق منها (طرطوس وحمص ودمشق وحماه) كما يوجد خط حديد بين طرطوس و الني تزنبط بعدة مناطق (حصص وحماه ودمثق) كما بوجد خط حديد بين القامشلي و عدة مناطق وهي (الحسكة ودير الزور و الرقة وحماه وحمص)ناحظ من خلال ما سبق ان سوريا قد اهنمت بوسائل النقل من خلال نوفير خطوط سكك ونك حديد في مناطق مختلفة بالإضافة إلى وسائل نقل اخرى كخطوط شُاحنات النقل للبضائع و المسافرين إضافة إلى النقل الجوي. 


\section{r. - الجاتب التطبيفي}

تم جمع البيانات عن السباحة في سوريا لعدة متغير ات نوضيحية ومتغير معتمد حيث نم جمع البيانات من احد مو اقع الانترنيت (wwwllsfare.com)

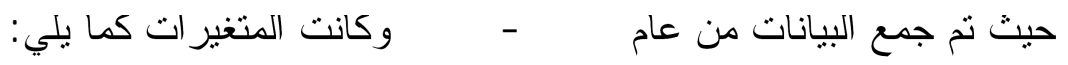
P=اسعار التذاكر (باليرة السورية) X1

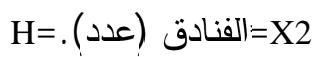
F=.الاسرة (عدد):X3

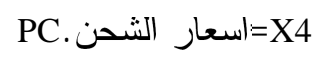
PD= تخفيض على التذاكر=X5

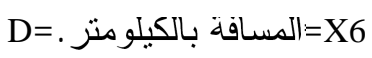
T= المتغير الاستجابة وهو عدد الزوار او السياح القادمين إلى سوريات 1 - تحليل البيانات يمكن كثابة نمودج الانحدار بدلالة المتغير ات المدروسة وكما يلي: $\mathrm{T}=\mathrm{b} 1 \mathrm{P}+\mathrm{b} 2 \mathrm{H}+\mathrm{b} 3 \mathrm{~F}+\mathrm{b} 4 \mathrm{PC}+\mathrm{b} 5 \mathrm{PD}+\mathrm{b} 6 \mathrm{D}$

تم تحليل البيانات من حيث إيجاد معادلة الانحدار التي توضح العلاقة بين المنغير ات المسنقلة و المتغير المعتمد وكان نموذج الانحدار كما يلي: $\mathrm{Y}^{\wedge}=0$ + 3.44 X1 - 338909 X2 + 594932 X3 - 13869651 X4 -3.44 X5 + 14352719 X6

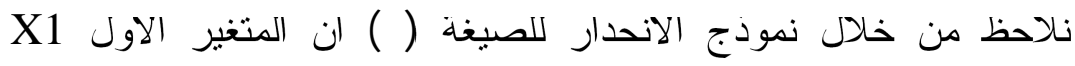

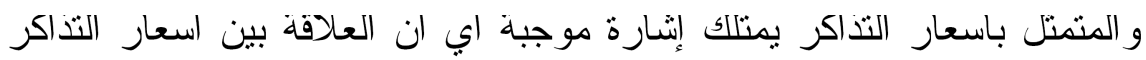
وعدد السياح علاقة طردية وهذا غير منطقي حيث ان العلاقة عكسية بين المتغيرين كذلك الحال بالنسبة للمتغير X2 و المتمتل بعدد الفنادق و الذي يمنتلك إنشارة سالبة اي ان العلافة عكسية بين المتغير X2 و المتغير المعتمد عدد

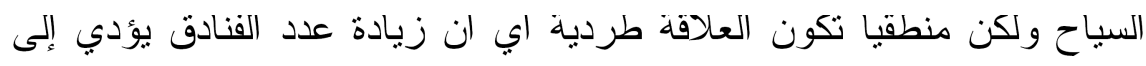


زيادة في عدد السياح حيث ان زيادة عدد الفنادق يؤدي إلى زيادة المنافسة بين إدار ات الفنادق في توفير اسعار اقل للحجز إضافة إلى المنافسة في تقديم افضل الخدمات للزبون.

السبب في ظهور منل هذه الحالة اي اختلاف الإشار ات لمعاملات الانحدار

مع منطقية العلاقة بين المتغير ات التوضيحية و المتغير المعتمد يعود إلى وجود

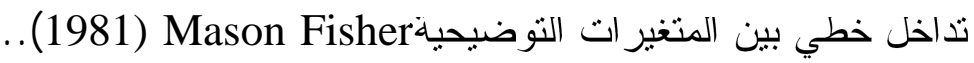
للكثف عن التداخل الخطي نجد مصفوفة الارنباط بين المتغيرات التوضيحية (Xunst and (Mason(1980)(X'X)وكما يلي:

الجدول -ro جدول يوضح مصفوفة الارتباط للمتغير ات التوضيحية، مصفوفة الارتباط=X3

\begin{tabular}{|c|c|c|c|c|c|c|}
\hline & $\mathbf{x 6}$ & $\mathbf{x 5}$ & $\mathbf{x 4}$ & $\mathbf{x 3}$ & $\mathbf{x 2}$ & $\mathbf{x 1}$ \\
\hline $\mathrm{x} 6$ & 1.00001 & 0.4914 & 0.9998 & 0.94388 & 0.76649 & 0.49131 \\
\hline $\mathrm{X} 5$ & 0.49142 & 1.00002 & 0.49879 & 0.36137 & 0.19009 & 1.00001 \\
\hline X4 & 0.99984 & 0.49879 & 1.00001 & 0.94039 & 0.75769 & 0.49868 \\
\hline X3 & 0.94388 & 0.36137 & 0.94039 & 1.00000 & 0.88810 & 0.36125 \\
\hline X2 & 0.76649 & 0.19009 & 0.75769 & 0.88810 & 1.00025 & 0.18993 \\
\hline X1 & 0.49131 & 1.00001 & 0.49868 & 0.36125 & 0.18993 & 1.00000 \\
\hline
\end{tabular}

بعد إجز اء اختبار t لتحديد معامل الارنباط الخاص بحجم العينة وجد ان قيمة t التي تلل على وجود ارتباط بين المتغيرات هي 7, · بالنسبة إلى العينة ع ا، بذلك نلاحظ إن هناك ارتباطات بين المتغير ات النالية:

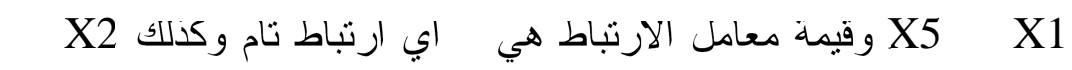

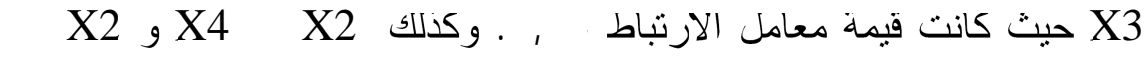

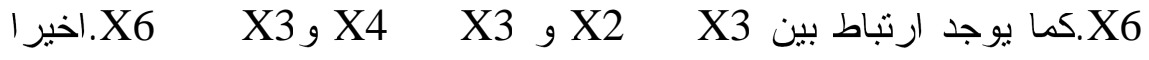

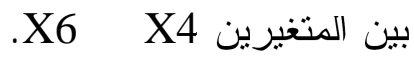




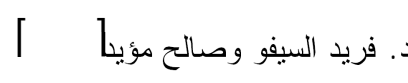
الاهمية الإستر اتيجية لقطاع النقل ..

كما يمكن رسم الثكل الانتشاري بين المتغيرات المسنقلة لتوضيح

الارتباطات الخطبة بين المتغير ات(Marquardt.Snee(1975 وكما يلي:

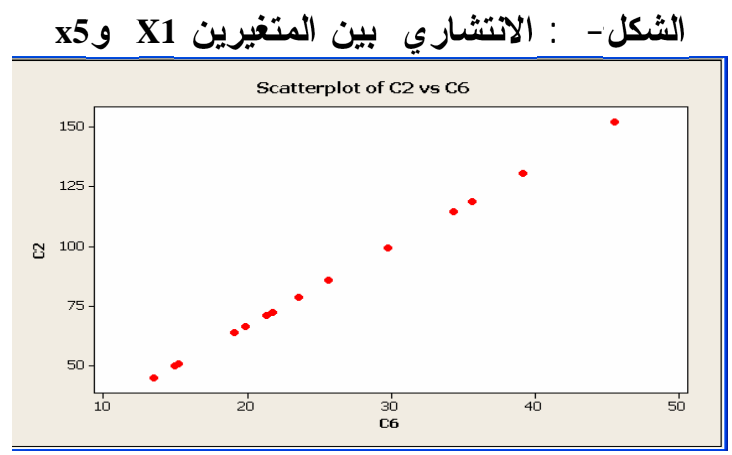

الشكل-r: الشكل الانتشاري بين المتغيرين X2 و33

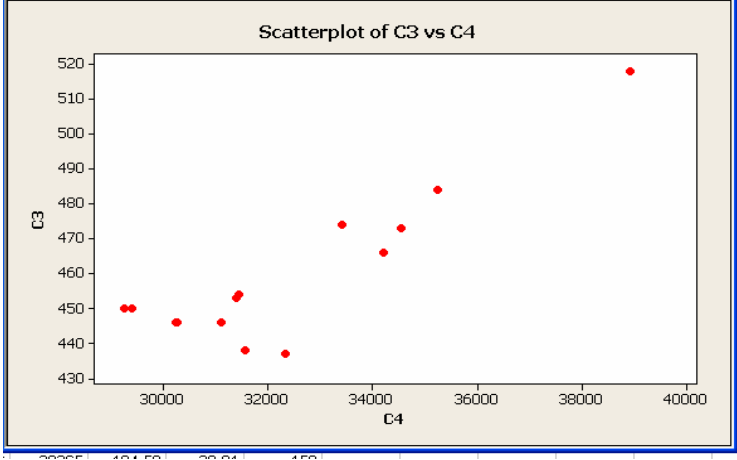

الشكل -r: الشكل الاتتشاري بين المتغيرين X2 و

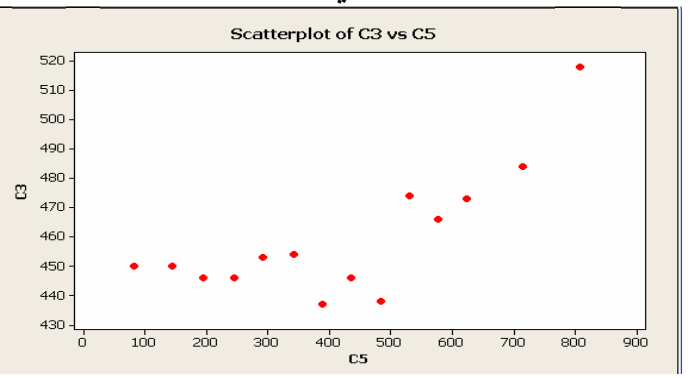


الشكل-ع: الثكل الاتنشاري بين المتفيرين X2 و

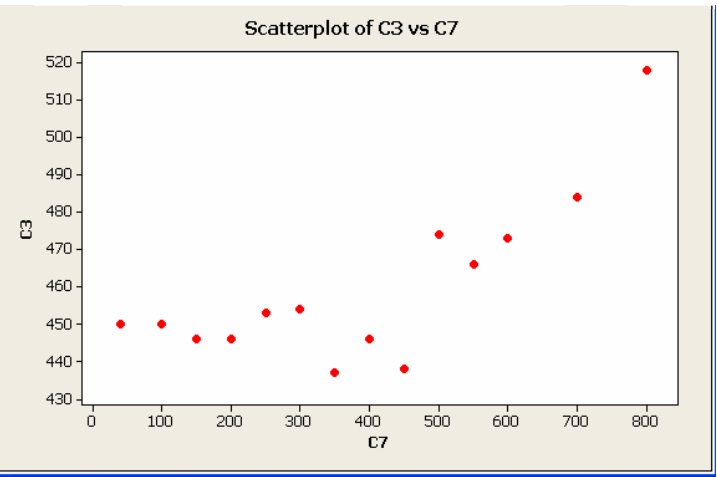

الثكل -0: الشكل الاتتشاري بين المتغيرين X3 و

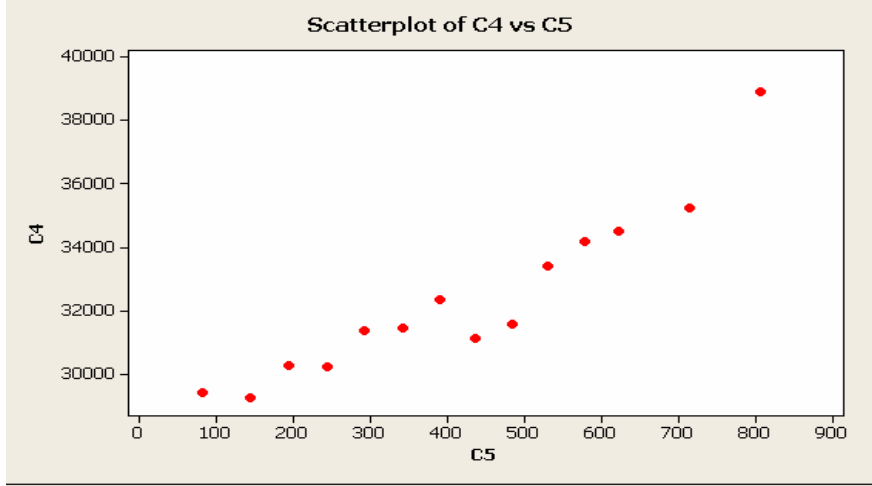

التكل -7: التكل الاتتشاري بين المتغيرين X3 و64

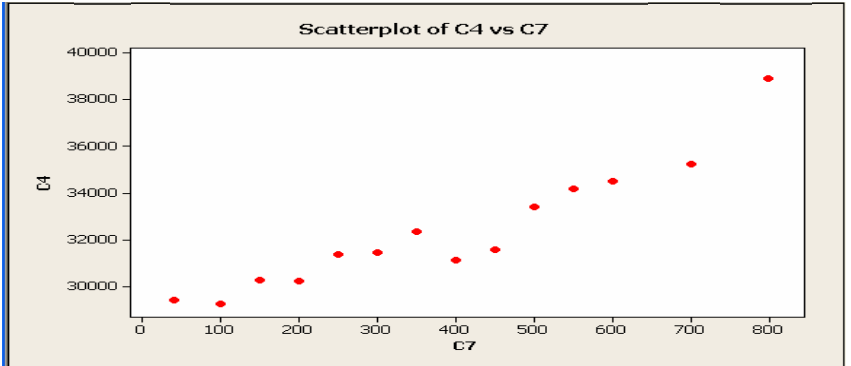




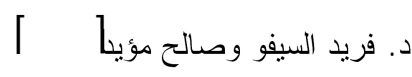
الاهمية الإستر اتيجية لقطاع النقل..

الشكل-V- الشكل الاتتشاري بين المتفيرين X4 وx6

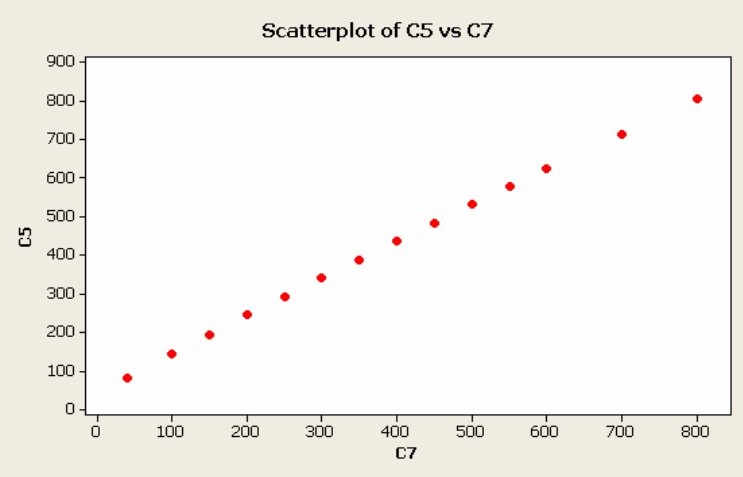

نلاحظ من خلال الإشكال الانتشارية اعلاه إن النقاط منقاربة فيما بينها مما

يدل على وجود نعدد علاقة خطية بين المنغيرات المستقلة. وللتخلص من هذه الارنباطات او تعدد العلاقة الخطبة نم استخدام احد الطرق الإحصائية المتحيزة للتخلص من هذا النداخل الخطي،حيث نم استخدام طريقة انحدار الحرف (Hoerl, Kennard, 1970a)

انحدار الحرف: نم رسم اتر الحرف Hoerl, Kennard, 1970b)و الذي

يصف تغير قيم المعاملات بحيث تثقارب كلما زادت قيمة K (حيث تتز اوح قيمة K بين I - . ) إلى إن تستقر هذه المعاملات وكما يلي:

Minitab الثكل -A: رسم اثر الحرف لمعاملات الانحدار من خلال برنامج

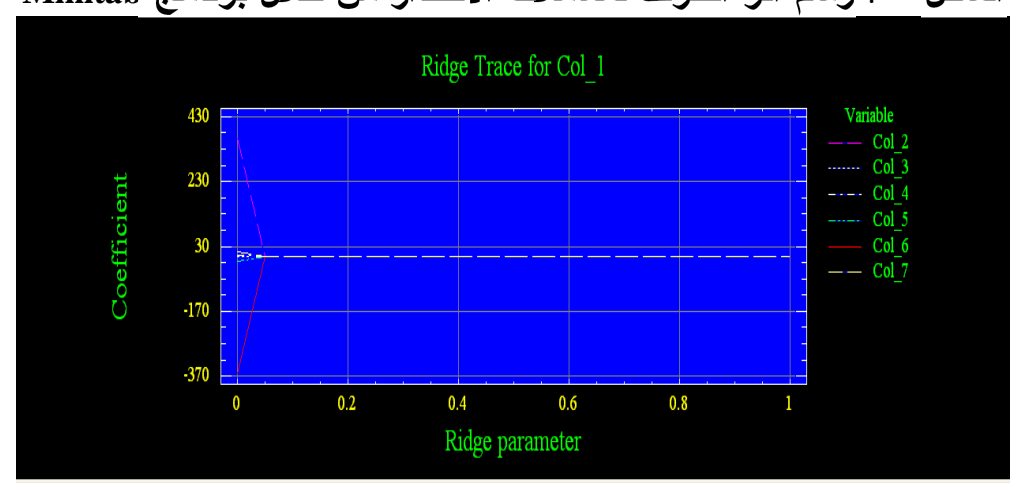


من خلال الرسم اعلاه تلاحظ المعاملات بدات تستقر عند قيمة تساوي r, · ثقريبا لذلك سنكون معاملات الانحدار كما يلي: $\mathrm{Y}^{\wedge}=0$ - 1654.6 X2 +6815.4 X2 +88.803 X3 +1073.98 X4 -5519.04 X5 + 1053.36 X6.

ويلاحظ من نموذج الانحدار اعلاه وبعد التخلص من تعدد العلاقة الخطية

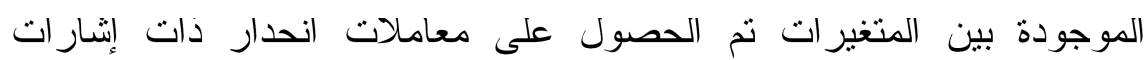
منطقية مما تعكس منطقية العلاقة الحقبقية بين المتغبرات المستقلة بالمتغير المعتمد. حيث ان المتغير X1 اي اسعار التذاكر اصبحت ذات إنـارة سالبة صحيحة اي علاقة عكسية مع المتغبر المعتمد عدد السباح القادمين بعكس ما

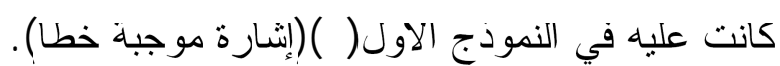
كذلك المتغير X2 و الذي كان بمنلك إثنارة سالبة في النمودج الاول وهي تدل على علاقة عكسية مع المتغير المعتمد عدد السياح القادمين وهذا مناف لمنطقية العلاقة الحقيقية بين المتغيرين(على الاقل في هذه الدراسة) ولكن بعد وهديز رفع التداخل الخطي الموجود اصبحت الإشارة موجبة صحيحة اي ان العلاقة طردية بين عدد الفنادق و عدد السياح.r

r - اختبار معنويه نمودج الاتحدار . تم احتساب جدول تحليل النباين وكما يلي: الجدول-ץs: جدول تحليل التباين

Source

Regression

Error

Total

\begin{abstract}
DF
\end{abstract}
$68.79284 \mathrm{E}+11 \quad 1.46547 \mathrm{E}+11$

$717060206214 \quad 2437172316$

$138.96344 \mathrm{E}+11$
MS

60.13 
فريد السيفو وصالح مؤيا 10 ] الاهمية الإسنر اتيجية لقطاع النقل..

$$
\begin{aligned}
& \text { يلاحظ من جدول تحليل التباين ان اختبار F اعطـى القيهــة المحسوبة }
\end{aligned}
$$

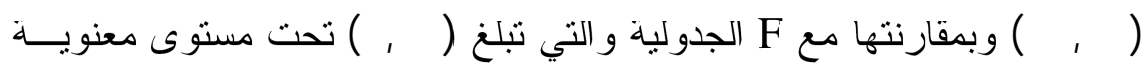

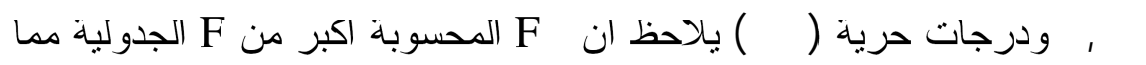

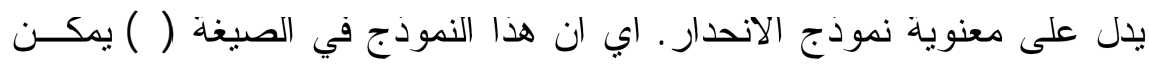

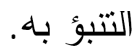

$$
\text { r -اختبار معنويه معاملات الاتحدار: }
$$$$
\text { تم إجر اء اختبار t لمعاملات الانحدار وكما يلي: }
$$$$
\text { الجدول -ع: اختبارات معنوية معاملات الانحار }
$$

$\begin{array}{lrrr}\text { Predictor } & \text { Coef } & \text { StDev } & \text { T } \\ \text { Constant } & -0 & 13194 & -0.00 \\ \text { X6 } & 14352719 & 4634908 & 3.1 \\ \text { X5 } & -344172802 & 243649763 & -1.41 \\ \text { X4 } & -13869651 & 4622028 & -3.00 \\ \text { X3 } & 594932 & 275938 & 2.16 \\ \text { X2 } & -338909 & 195306 & -1.74 \\ \text { X1 } & 343992629 & 243631956 & 1.41\end{array}$

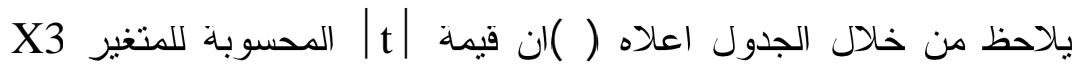

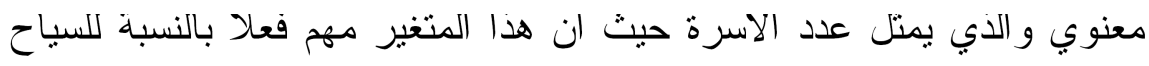
حيث ان هذا المتغير ياتي على اساس حصول السياح على عدد من الاسرة و الذي يرتبط هذا المتغير بالمتغير عدد الفنادق ويمكن ملاحظة ذلك من خلال

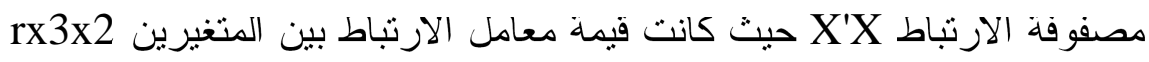

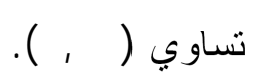

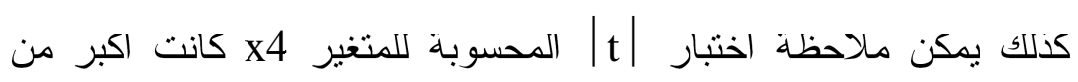

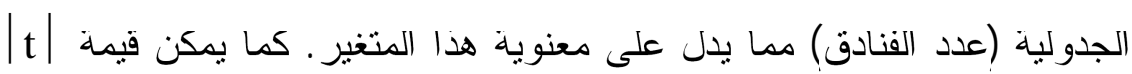


المحسوبة للمتغير X6 (المسافة بالكيلو متر) ايضا ظهرت معنوية اي انها تؤثر بشكل معنوي على المتغبر المعتمد(عدد السباح).

اما بقيت المتغير ات فقد ظهرت غير معنوية ولكن ومن خلال جدول تحليل التباين و اختبار Fلاحظ ان نمودج الانحدار كان معنوي ويمكن الاعتماد عليه في التنبؤ . بذلك بمكن كتابة النمودج الجديد بعد استبعاد المتغير ات الغير معنوية

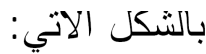
$\mathrm{Y}^{\wedge}=0+88.803 \mathrm{X} 3+1073.98 \mathrm{X} 4+1053.36 \mathrm{X} 6$

كما نم إيجاد معامل التحديد R2 حيث بلغت قيمته R2=98.1\% مما يدل على ان 9 \% من النغيرات الحاصلة في المتغير المعتمد سببها التغيرات الحاصلة في المتغير ات النوضيحية (المستقلة). الاستنتاجات و التوصيات: لقد توصل البحث إلى عدد من الاستتناجات و التوصيات وهي كما يلي: | الاستتتاجات:

لقد اظهرت الدر اسة وجود متغيرات معنوية لها تاتير مباشر على عدد من السياح القادمين إلى سوريا من مجموعة من المتغيرات المستقلة المستخدمة وهي (X6،X3،X4)حيث إن في بداية التحليل ظهر لدينا وجود تداخل خطي مني بين المتغيرات التوضيحية لذلك تم استخدام احد الطرق الإحصائبة المتحيزة (انحدار الحرف) للتخلص من هذا التداخل الخطي. 


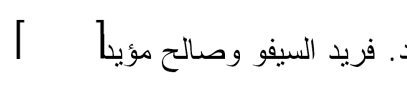
الاهمية الإسنر اتيجية لقطاع النقل..

قيام الحكومة السورية بالاهتمام بالنقل كونه احد اهم ادو ات تقعيل وتطوير قطاع السياحة وذلك بتوفير خطوط سكك الحديد المختلفة إضافة إلى وسائل نقل

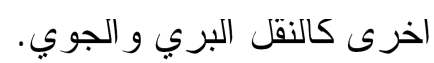

اتخذت الحكومة السورية إجراءات عملية فاعله ومحفزة لعملية الجذب

السياحي خصوصا السياح العرب من بلاد الاغنز اب وخصت منهم السوريين وذلك بقيامها فتح قنو ات الاتصال معهم.

تعد السياحة بالنسبة لسوريا اليوم موردا من مو ارد دخلها القومي لما تجلبه لها من عملات صعبذ إلى جانب العمل لالاف من ابنائها.

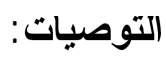

فتح افاق التعاون السياحي والنقل بين سوريا والوطن العربي إضافة إلى

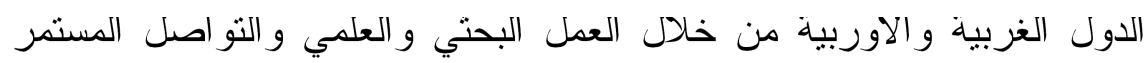

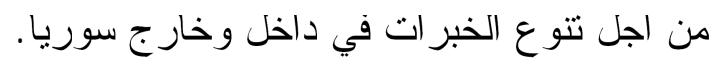

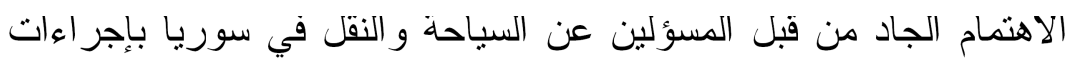
التتشيط لهذين القطاعين لغرض زيادة السياحة الخارجية.

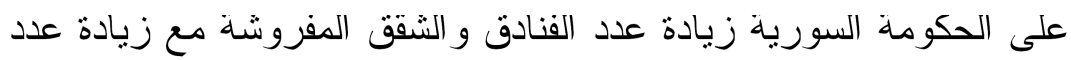

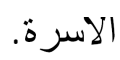

على الحكومة السورية فتح حدائق وملاهي للاطفال على غرار مدن الالعاب العالمية المنطورة مع تسهيل الوصول لها وتقليص المسافات بالاهتمام

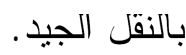

يجب على الحكومة السورية النواصل الجاد والمستمر من اجل جعل

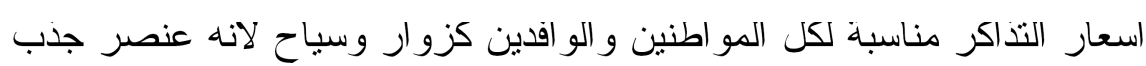
سياحي مهم. 


\title{
The Strategic Importance For Transportation Sector And Its Effects to Increase and Grown The System Attractive Tourism Areas In Syria: Economical- Statistical Study
}

\author{
Dr. Fareed Isma'eel Ameen \\ Lecturer, Department of \\ Economics, College of \\ Administration \& Economics, \\ Mosul University
}

\author{
Salih Mo'ayed Shukur \\ Assistant Lecturer, Department \\ of Statistics, College of \\ Computers Science \& \\ Mathematics, Mosul University
}

\begin{abstract}
This paper aims to study the consideration, that there is a power relationship between tourism and transportation sectors, specifically Syrian railway sector influencing tourism sector today by many different problems which correlated to art cases be longed to it as transportation. So as it must be do Syrian tourism sector through increasing and grown transportation sector. Which play important role in Syrian attractive tourism movement and assistant it with investment to offer successfully solutions for movement tourism in it.
\end{abstract}




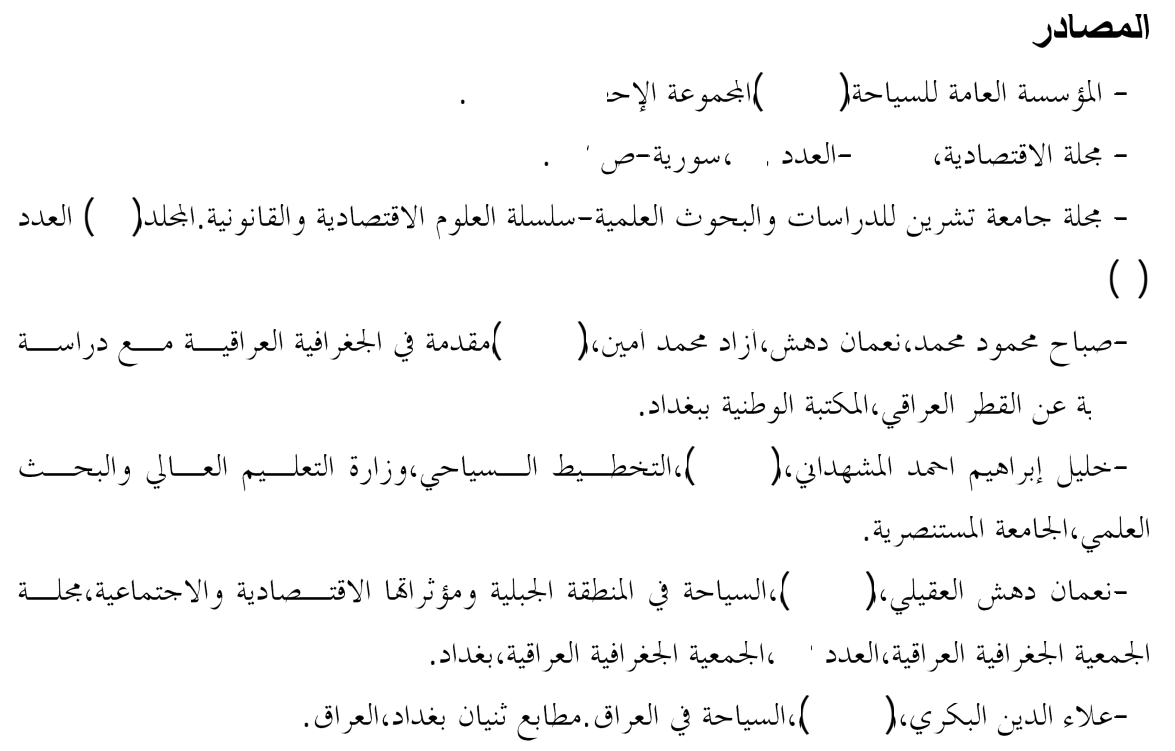

7- Fisher J.C. and Mason R.L.(1981) "The Analysis of Multicollinear data in criminology" Academic Press Inc.

8- Hoerl A.E. and Kennard R.W.(1970a)."Ridge regression: Biased estimation for nonorthogonal."tecnometrics 12 55-67.

9- Hoerl A.E. and Kennard R.W.(1970b)."Ridge regression: Applications to nonorthogonal problems."Technometrics 12 69-82.

10- Gunst R.F.and Mason R.L.(1980) "Regression analysis and its Application " Marcel Dekker inc. New York U.S.A.

11- Marquardt. D. T. and Snee R.D.(1975) "Ridge Regression in practice "The American statistican Vol.29.No.1.p(3-20). 